Sharif University of Technology
Scientia Iranica
Transactions E: Industrial Engineering
h.te://scientiairanica.sharif.edu
IRAN ICA

\title{
Renewable policies and challenges by 2020 in Greece: A questionnaire survey
}

\author{
A. Bitzenis ${ }^{a}$, P. Kontakos ${ }^{b, c, *}$, and C. Kafteranis ${ }^{c}$ \\ a. Department of International and European Studies, University of Macedonia, Research Leader of European Research Fund \\ Thalis, 156 Egnatias Str., GR 54006, Greece. \\ b. School of Business \& Management, University of Central Lancashire, 12-14 University Avenue, CY 7080, Cyprus. \\ c. University of Macedonia, Department of International and European Studies, University of Macedonia, 156 Egnatias Str., GR \\ 54006, Greece.
}

Received 1 December 2015; received in revised form 6 October 2016; accepted 31 October 2016

\section{KEYWORDS}

Renewable energy; Government policy; Questionnaire survey; Shadow economy; Greece.

\begin{abstract}
In a notable change from the position in the past, the Greek government took steps to commit itself to greening the economy and determining policies and actions to boost the utilization of renewable energy. The aim of the paper is, firstly, to present the latest developments on the renewable energy policy in Greece, the current achievements and impediments to the implementation of planned reforms in the accomplishment of its 2020 targets, and the specific policy measures introduced; secondly, to discuss the pace of respective developments in other EU-28 member countries; thirdly, to verify the achievements of the government towards reversing previous bureaucratic, prone-tocorruption procedures through a questionnaire survey and stratified interviews with market participants. Research survey results from our survey and interviews conducted in the second semester of 2014 are respectively presented. The majority of respondents expect to see the targets set in the National Renewable Energy Action Plan reached by 2020. The paper and questionnaire survey have been conducted under the auspices of the European research program THALES, aiming to measure various aspects of the shadow economy and the areas of renewable energy trade and finance in Greece.

(C) 2018 Sharif University of Technology. All rights reserved.
\end{abstract}

\section{Introduction}

Climate change is associated with enormous and multidimensional challenges and opportunities, both for governments and businesses. Tackling humaninduced emissions of greenhouse gases, particularly those sourced from fossil energy production, is an issue highly prioritized in the global political agendas of the World Economic Forum (WEF) annual meetings in Davos and of the annual group of 20 summits. Recently, at the United Nations Sustainable Development

\footnotetext{
*. Corresponding author.

E-mail address: pkontakos@uclan.ac.uk (P. Kontakos)
}

doi: $10.24200 /$ sci. 2017.4407
(UNDP) Summit on 25 September 2015, global leaders agreed on the 2030 agenda for sustainable development, which comprises a list of 17 Sustainable Development Goals (SDGs) to end poverty, fight inequality and injustice, and tackle climate change problems by 2030 .

Respectively, during the last 20 years, the European Union has been actively and consistently involved in the worldwide battle against climate change problems. In an era where the environment is challenged and the pricing of energies is questioned, the view of $\mathrm{EU}$ is that future champions will consist of energysaving and low-carbon economies. As a provisional step for 2020, the EU has laid down a series of determined climate and energy targets, known as "20-20-20 targets by 2020 " or the " $3 \times 20$ " policy. This included commitments to squeeze Greenhouse gas emissions by $20 \%$ 
from 1990 levels, increase the proportion of EU final energy consumption generated from renewable resources to $20 \%$, and advance energy efficiency by $20 \%$. This " $3 \times 20$ " package consists of a part of a wider European energy strategy aimed at achieving sustainable, secure and affordable energy for Europeans.

Accomplishing these targets is also linked to technological advances and innovations which create many prospects for respective businesses and industries. For example, indicatively, photovoltaic energy has, nowadays, amplified its significance in electrical power applications [1]. Recent advancements in photovoltaic (PV) system technologies have cut their investment cost and facilitated the building of large PV farms for bulk power generations [2]. Also, hydrogen is often considered the best means to store energy coming from renewable and irregular power sources [3]. Photovoltaic generation models employ artificial intelligence techniques as a function of weather parameters [4]. Further, Ohara et al. [5] discussed the case of residential solar combined heat and power generation using solar thermoelectric generation, and Harman and Zunger [6] accommodated a list of research opportunities in photovoltaic semiconductors. In parallel, pricing policy considerations, particularly with reference to managing the feed-in system of RES on the side of government consist of a detrimental aspect for fostering future investment in PV projects, and also one can indicatively refer to the studies of Faridimehr and Niaki [7] and also Shavandi and Zare [8]. Further, in order to undertake a more holistic decision-making process, where multiple objectives (economic, social, environmental, regulatory, technical, technological) are pursued concurrently, more formal decision-making methods can also be exploited, such as the application of diverse Multiple-Criteria Decision-Making (MCDM) techniques to support appraisal and selection processes in engineering [9].

The EU energy and climate package, however, have been criticized in recent years for not succeeding to achieve the anticipated results and encompassing many, unexpected or unintentional, impacts on energy markets and industries. Many countries are on the right track to reach their $3 \times 20$ targets, and the EU-28 as a whole has made significant improvement towards accomplishing the objectives. But, whether this is mainly due to committed policies or to external factors is well debatable. The economic crisis has also facilitated achievements to appear better than they might actually be in countries such as Spain, the Netherlands, Italy, and probably Greece, because crisis has altered and curtailed their demands as well as consumption attitudes and levels against which the targets are calculated.

Greece is characterized by ample wind and solar energy resources potential and is determined to accomplish this prospective. The renewable energy sector also offers the potential to develop new industrial infrastructure, particularly related to innovative activities. To facilitate renewable energy projects, the Greek government has significantly enhanced the investment framework recently by increasing feed-in tariffs, removed and replaced previous complex licensing and bureaucratic procedures to encourage private sector investment, and introduced stronger motives for local acceptance.

Unlike the situation in previous years, the government has adopted solid targets, policies, and measures to increase the use of renewable energy. In alignment with its EU obligation, the country aims to increase the share of Renewable Energy Sources (RES) in gross final energy consumption to $20 \%$ by 2020 ; also, renewables are expected to supply $40 \%$ of electricity generation by 2020.

Unfortunately, the growth of renewable electricity in Greece has failed to achieve meaningful levels in the past [10] despite a notable private initiative [11]. The prospect for energy efficiency advances in Greece is substantial, particularly when the country's relatively high energy intensity (total energy consumption divided by Gross Domestic Product) of 203 toe/MEUR'2000 is considered that lies in the upper range of the majority of the European countries, which is on average 185 toe/MEUR'2000. This is also due to the lack of constant, determined and structured energy-saving campaigns together with the rather inexistent "energysaving culture" [12].

Within the aforementioned background, our aim in this paper is to measure the current progress in Greece towards the achievement of the overall RES targets as have been set in the National Renewable Energy Action Plan by 2020 and assess their attainability.

The paper is structured as follows. In the next section, the latest developments on the renewable energy policy in Greece, the current achievements and impediments to the implementation of planned reforms in the accomplishment of the 2020 targets, the specific policy measures introduced, and also the pace of respective developments in other EU-28 countries are presented; the third section provides a literature review on the subject, followed in the fourth section by an overview of our aims and methodology under the research program THALES; in the fifth section, the achievements of the Greek government towards reversing previous bureaucratic, prone-to-corruption procedures verified through a questionnaire survey and stratified interviews conducted in the second semester of 2014 are discussed. Respectively, research survey results from our survey and interviews are presented. The final results of the survey are expected to support the development of useful proposals for facilitating the Greek government to fine-tune its intermediate 
policy goals, to embolden its fight against bureaucratic and corrupted procedures, and ensure that its 2020 renewable energy targets will be achieved. In the last section, the main conclusions of the article are summarized.

\section{Renewable energy developments in Greece and EU}

\subsection{Supply and demand}

According to the data from the International Energy Agency (IEA, 2014) in 2012, Total Primary Energy Supply (TPES) in Greece amounted to 27 tons of oil equivalent (Mtoe) [13]. Lignite and renewable energy are the prime country's sources and account for almost one-third of its energy requirements and the whole local production. The rest of the two thirds of TPES are oil and natural gas which are almost 100\% imported. Although oil remains the most significant energy source, over the years, it has been progressively replaced by lignite and more recently by natural gas. Correspondingly, Total Final Consumption (TFC) amounted to 20.6 Mtoe in 2009. Similar to TPES, it increased rapidly in the period of 1990 to 2007 at a compound annual rate of $2.5 \%$, when it turned south as a consequence of the deteriorating economic conditions.

RES, specifically, accounted for 2,5 million Mtoe or approximately the equivalent of $9.4 \%$ of TPES in Greece in 2013, according to Eurostat. Their proportion in TPES had been constant in the range of $5 \%$ to $6 \%$ in the last 20 years up to 2010 when it was only amplified notably at $7.5 \%$ (see Figure 1 ).

Biomass and renewable wastes provided most of renewable energy (43\%) in 2013, totaling 1.1 Mtoe. They are comprised of fuel wood, vegetal waste, and liquid biofuels. Hydropower generated $22 \%$ of total renewable supply, reduced from $28 \%$ in 2010 . Over the last decade, its share in TPES averaged 1.3\%,

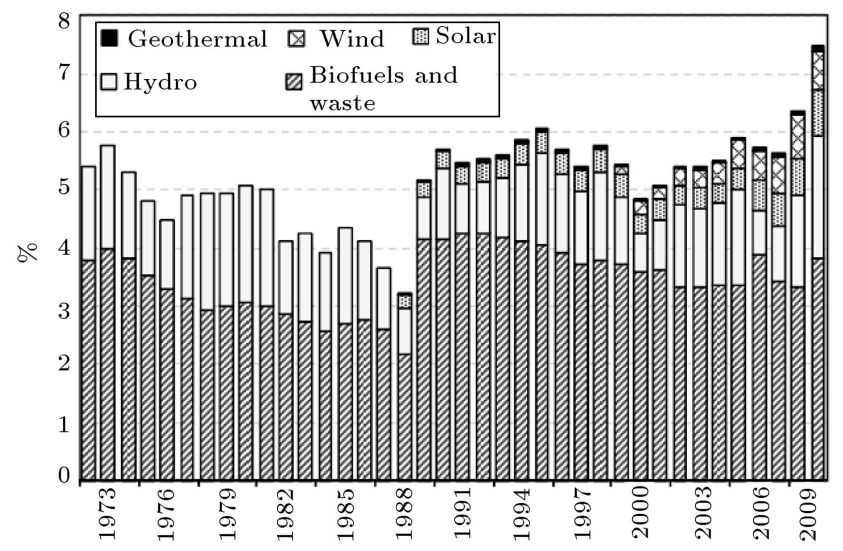

Figure 1. Renewable energy as a percentage of total primary energy supply in Greece, 1973 to 2010 (Source: Energy Balances of OECD Countries, IEA/OECD Paris, 2011). ranging from $0.6 \%$ to $2.1 \%$, according to hydrological conditions.

Solar energy is primarily used for directly heating water; its utilization for electricity generation is still insignificant. This solar thermal energy supply reached 0.5 Mtoe in 2013 , or $20 \%$ of renewable energy, which consists of the highest share of solar energy among EU-28 member countries, ahead of Spain with $15 \%$, after Malta with $73 \%$, and Cyprus with $64 \%$. Wind power supply has increased rapidly, at a lesser pace though, standing at $14 \%$ of renewable energy when equaling solar energy in 2009. Greece ranks in 2013 at the seventh position regarding the share of wind power in renewable energy among the EU-28 member countries [14].

Overall, $40 \%$ of primary renewable energy in Greece is utilized in buildings for heat generation, and roughly the same share is directed into electricity generation. The rest is consumed in industry and agriculture. Notwithstanding the front place in terms of primarily solar and yet wind energy, Greece maintains a relatively low proportion of total RES in TPES. Further, RES accounted in 2013 for $21.2 \%$ (in $2010,12.3 \%$ ) of gross electricity generation (\% of gross electricity consumption), versus the EU-28 average of $25.4 \%$ (in 2010, 19.6\%) per data from Eurostat [14]. The country maintains, however, large untapped RES. The strategies and roadmaps to develop them are elaborated in the 2010 National Renewable Energy Action Plan (refer below under Policies and Reforms).

\subsection{Policies and reforms}

The analysis of the RES legislation, policies, and reforms discussed in the current section has been retrieved, primarily from the IEA and secondary from the DG ENER. The main institutions involved in the formulation, implementation, and administration of renewable energy policy in Greece are: The Ministry of Environment, Energy and Climate Change (MEECC); the Regulatory Authority for Energy (RAE), which has a key function in licensing projects for electricity generation from RES; the Hellenic Transmission System Operator (HTSO), responsible for the electricity network development to accommodate capacity increases in renewable energy generation; the Public Power Corporation (PPC) is the system operator on the non-interconnected islands; the Municipal, prefectural, and regional authorities also involved in the licensing process of renewable energy projects; the Centre for Renewable Energy Sources and Saving (CRES), supervised by MEECC, is the national body responsible for promoting RES, energy efficiency and research and providing assistance in the formulation of energy policy.

European Union requirements direct the exercising of renewable energy policy in the country. Directive 2009/28/EC9 sets a binding goal to boost the pro- 
portion of RES in gross final energy consumption to $18 \%$ by 2020 (from $6.9 \%$ in 2005 ) which has replaced prior non-obligatory goals set in 2010 related primarily to biofuels and electricity generation from RES. The respective goal for the entire EU is set at $20 \%$ by 2020 . Another discrete goal set by the directive refers to the provision of $10 \%$ of the final energy in transportation by RES in the same period [15-17].

The directive was converted into national legislation by Law $3851 / 2010$, which specifies an even more striving goal than the directive: $20 \%$ of gross final energy consumption versus the $18 \%$ compelled by the directive. The same law also places a particular goal for RES to produce $40 \%$ of all electricity in 2020 and supplying $20 \%$ of primary energy for heating and cooling in 2020.

Law 3851/2010 additionally initiates many amendments to prior legislation. It makes the licensing procedures simpler, reworks the feed-in tariff scheme, and deals with local obstacles to RES projects. It also puts in place precise regulations related to the energy performance and the usage of renewable energy in new buildings (as also stipulated by the Energy Performance of Buildings Regulation).

The government aims to achieve the 2020 renewable energy goals by a mixture of policies and measures on energy efficiency and renewable energy, which are contained and elaborated in the National Renewable Energy Action Plan (NREAP) since July 2010. NREAP describes three scenarios with different outcomes for the final energy consumption, RES contribution, and capacity. The respective projections are shown in Table 1. Under these scenarios, electricity provides definitely the vital boost in RES utilization.

During the years 2004-2009, RES projects were sponsored by the government investment schemes under the National Development Law (L3299/2004, amended by L3522/2006). It was a framework law, encompassing all economic sectors. The subsidy scheme covers the total investment cost and the applicable rates vary among 20-60\% depending on the regional and corporate profiles and based upon criteria, such as the unemployment rate/income per capita and size, respectively. Tax deductions, reached $20 \%$ of the purchase cost (with a cap of EUR 700 per system), were awarded for small domestic RES systems (e.g., primarily used for the purchase of solar thermal systems, small wind turbines, solar photovoltaic-PV systems).

By the end of 2009, approximately 500 million EUR in investment subsidies had been established per the 2004 law. Upon termination, a new Development and Investment Law 3908/2011 was introduced which renders aid to RES investments (excluding PV plants) via a mixture of tax incentives and grants. Further, approximately 190 million EUR were received in subsidies in the years 2000-2006 under the Operational
Programme for Competitiveness, i.e. a European Union mechanism to sponsor low-income regions.

Per NREAP, the share of electricity generation from RES should increase more than three times from its 2010 level in order to qualify the target of $40 \%$ by 2020. The specific targets considered under the NREAP's compliance scenario are based on the following projections for new capacities: wind power (roughly $7.5 \mathrm{GW})$ by 2020 , jointly with PVs $(2.2 \mathrm{GW})$, concentrating solar power plants (250 MW), of bioenergy (biogas and solid biomass) installations (250 MW), small hydro plants (250 MW), and geothermal energy $(120 \mathrm{MW})$. Also, new installed capacities should be accounted for large hydro plants (350 MW) and pumped storage plants ( $880 \mathrm{MW})$, leading overall to a $40 \%$ share for renewable energy in electricity production [15]. To achieve the aim, the government has augmented feed-in tariffs and shortened the duration of licensing procedures. The transmission system operator has also set a plan for developing the transmission network to accommodate a large increase in renewable energy supply. PPC, the major power generator, is setting up to expend billions of euros in the near-term period in renewable energy.

In addition to investment subsidies, the government has used (since 1994) feed-in tariffs to encourage investments in electricity generation from RES. The current tariff system was introduced by Law $3851 / 2010$, revising the 2006 system and increasing feed-in tariffs, in particular for wind and solar powers, where Greece has a large untapped potential. Tariffs are now standardized per technology specifications, instead of being identical, and a guarantee of 12 years is granted with an option of extension to 20 years. The tariff rate ranged from $€ 88 / \mathrm{MWh}$ for wind to $€ 285 / \mathrm{MWh}$ for solar thermal with storage and $€ 550 / \mathrm{MWh}$ for PVs in households and small corporations [15]. For comparison, the average wholesale electricity price in Greece for the years 2007-2009 was $€ 69 / \mathrm{MWh}(€ 58 / \mathrm{MWh}$ in the first quarter of 2015).

The location (siting) of renewable energy installations at regional and local levels is guided by the Special Spatial Planning Framework for the Development of Renewable Energy Sources and Land Management (SPPF-RES), established at the end of 2008. It prioritizes specific regions to the development of renewable energy facilities and facilitates the environmental permitting.

Licensing procedures of renewable energy projects in the country had previously been a prolonged and compound process. Law $3851 / 2010$ has altered this by streamlining licensing procedures and initiating timesaving issuing deadlines. Licensing procedures were eased in two ways. First, the Regulatory Authority for Energy (RAE), replacing the minister, undertakes the power for issuing the electricity-generating license 
Table 1. Main projections for 2010-2020 in the National Renewable Energy Action Plan by scenario.

\begin{tabular}{|c|c|c|c|c|c|c|c|c|c|}
\hline & \multicolumn{3}{|c|}{2010} & \multicolumn{3}{|c|}{2015} & \multicolumn{3}{|c|}{2020} \\
\hline & 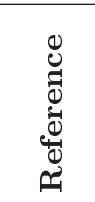 & 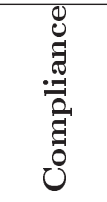 & 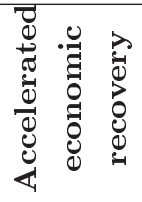 & 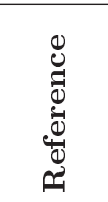 & 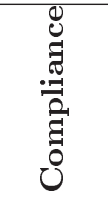 & 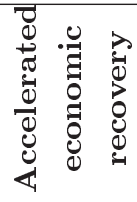 & 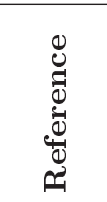 & 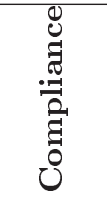 & 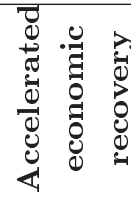 \\
\hline $\begin{array}{c}\text { Electricity } \\
\text { generation }(\mathrm{TWh})\end{array}$ & 58.86 & 58.86 & 58.86 & 64.13 & 61.47 & 62.09 & 72.18 & 68.46 & 72.28 \\
\hline $\begin{array}{l}\text { Total RES } \\
\text { electricity }\end{array}$ & 7.84 & 7.84 & 7.84 & 14.16 & 16.97 & 18.26 & 20.23 & 27.27 & 29.74 \\
\hline $\begin{array}{c}\text { \%RES inelectricity } \\
\text { generation }\end{array}$ & $13 \%$ & $13 \%$ & $13 \%$ & $22 \%$ & $28 \%$ & $29 \%$ & $28 \%$ & $40 \%$ & $41 \%$ \\
\hline $\begin{array}{c}\text { RES installed } \\
\text { capacity }(G W) \\
\text { of which }\end{array}$ & 4.11 & 4.11 & 4.11 & 7.13 & 8.66 & 9.33 & 9.91 & 13.27 & 14.72 \\
\hline Biomass/biogas & 0.06 & 0.06 & 0.06 & 0.05 & 0.12 & 0.12 & 0.05 & 0.25 & 0.25 \\
\hline $\begin{array}{c}\text { Hydro } \\
\text { (excluding pumping) }\end{array}$ & 2.54 & 2.54 & 2.54 & 2.89 & 2.92 & 2.91 & 2.91 & 2.95 & 2.95 \\
\hline Wind & 1.33 & 1.33 & 1.33 & 3.78 & 4.3 & 4.74 & 6.25 & 7.5 & 8.25 \\
\hline Solar PV & 0.18 & 0.18 & 0.18 & 0.41 & 1.27 & 1.51 & 0.7 & 2.2 & 2.9 \\
\hline CSP & 0.00 & 0.00 & 0.00 & 0.00 & 0.03 & 0.03 & 0.00 & 0.25 & 0.25 \\
\hline Geothermal & 0.00 & 0.00 & 0.00 & 0.00 & 0.02 & 0.02 & 0.01 & 0.12 & 0.12 \\
\hline $\begin{array}{c}\text { Final energy } \\
\text { consumption (Mtoe) } \\
\text { of which RES }\end{array}$ & 21.53 & 21.53 & 21.53 & 22.2 & 21.33 & 21.56 & 24.19 & 23.08 & 24.64 \\
\hline Biomass/biogas & 1.01 & 1.01 & 1.01 & 0.88 & 1.13 & 1.13 & 0.93 & 1.22 & 1.29 \\
\hline Solar heat & 0.22 & 0.22 & 0.22 & 0.24 & 0.27 & 0.22 & 0.27 & 0.36 & 0.41 \\
\hline Geothermal & 0.02 & 0.02 & 0.02 & 0.00 & 0.02 & 0.03 & 0.00 & 0.05 & 0.06 \\
\hline Ambient heat & 0.02 & 0.02 & 0.02 & 0.12 & 0.13 & 0.21 & 0.19 & 0.28 & 0.36 \\
\hline $\begin{array}{l}\text { Biofuels in } \\
\text { transport }\end{array}$ & 0.11 & 0.11 & 0.11 & 0.28 & 0.39 & 0.39 & 0.41 & 0.62 & 0.69 \\
\hline $\begin{array}{l}\text { \% RES in gross final } \\
\text { energy consumption }\end{array}$ & $9 \%$ & $9 \%$ & $9 \%$ & $12 \%$ & $15 \%$ & $16 \%$ & $14 \%$ & $20 \%$ & $21 \%$ \\
\hline
\end{tabular}

Source: National Renewable Energy Action Plan 2010.

from RES or highly efficient cogeneration, i.e. the first main license in the licensing process. Secondly, the formerly distinct requirements for preliminary environmental impact assessment and evaluation as well as ultimate environmental terms endorsement have been amalgamated into a sole process.
Under the prior licensing system, the authorization procedures were exceeding 3.5 years typically for small hydropower plants and wind farms and reaching 7 years in specific cases. The average in the present system is approximately a year for PV installations with capacities of less than $2 \mathrm{MW}$ and approximately 
2 years for other renewable energy plants. For very large projects, Law 3851/2010 has initiated fast-track licensing with the entire licensing process, requiring merely 4 to 6 months. Fast-track licensing is relevant for investment projects of a minimum of 200 million EUR, or 75 million EUR, if they generate at least 200 new jobs. The process is administered by the Invest in Greece Agency.

HTSO considers that the implementation of the present National Transmission Development Plan will facilitate the linking of around $8.5 \mathrm{GW}$ of renewable energy capacity in the interconnected system. This is in alignment with the compliance scenario of the NREAP. Nevertheless, primarily, tough public and community resistance renders significant obstacles and delays in the building up of new transmission projects. Law $3851 / 2010$ deals with this issue by partially reassigning revenues from renewable energy producers toward the local communities.

The government projects aim to boost the proportion of renewable energy in primary energy for heating and cooling to $20 \%$ by 2020 , primarily via the constant expansion of solar thermal installations in the residential and service sector, the smoothening of the biomass proportion in the residential sector, and progressive raising of heat pumps utilization.

\subsection{EU-28 energy targets by 2020 regarding RES}

Europe stands at an unparalleled junction for its energy prospect. To accomplish its energy and climate goals of "20-20-20 by 2020" and secure the changeover to a low-carbon economy by 2050 while nurturing growth and jobs, Europe is necessary to endow the upgrading of the energy infrastructure in the next years [18]. The Energy Policy for Europe, settled by the European Council in March 2007, establishes the Union's core energy policy objectives of competitiveness, sustainability, and security of supply. The internal energy market has to be accomplished in the upcoming years, RES should deliver $20 \%$ to the final energy consumption by 2020, greenhouse gas emissions are required to drop by $20 \%$, and energy efficiency benefits need to provide $20 \%$ savings in energy consumption. Particularly, the targets and distance that have to be covered by 2020 per EU28 country members in order to achieve their binding requirements are depicted in Figure 2 [19]. Overall, until the end of 2014, RES reached $16 \%$ share in the energy consumption of the EU. Nine member countries have already achieved their targets toward 2020, while others need to strengthen their efforts. Further, recent economic uncertainties have stalled investment flows in RES in Europe due to policy shifts and declining RES technology costs $[20,21]$.

\section{Previous research survey-related studies}

No analogous questionnaire survey has been conducted in Greece with the direct involvement of market participants to assess the current status of achievements of the government towards reversing previous bureaucratic, prone-to-corruption procedures.

Other related studies mainly focus on assessing the levels of social acceptability for selected Renewable Energy Sources (RES) technologies, mainly wind, small hydro and PVs. A survey which took place in the broad region of central Peloponnese (South Greece), where a remarkable number of RES-based installations have already been developed, indicated high levels of acceptability of RES applications by local inhabitants [22]. Although this has raised public opposition in

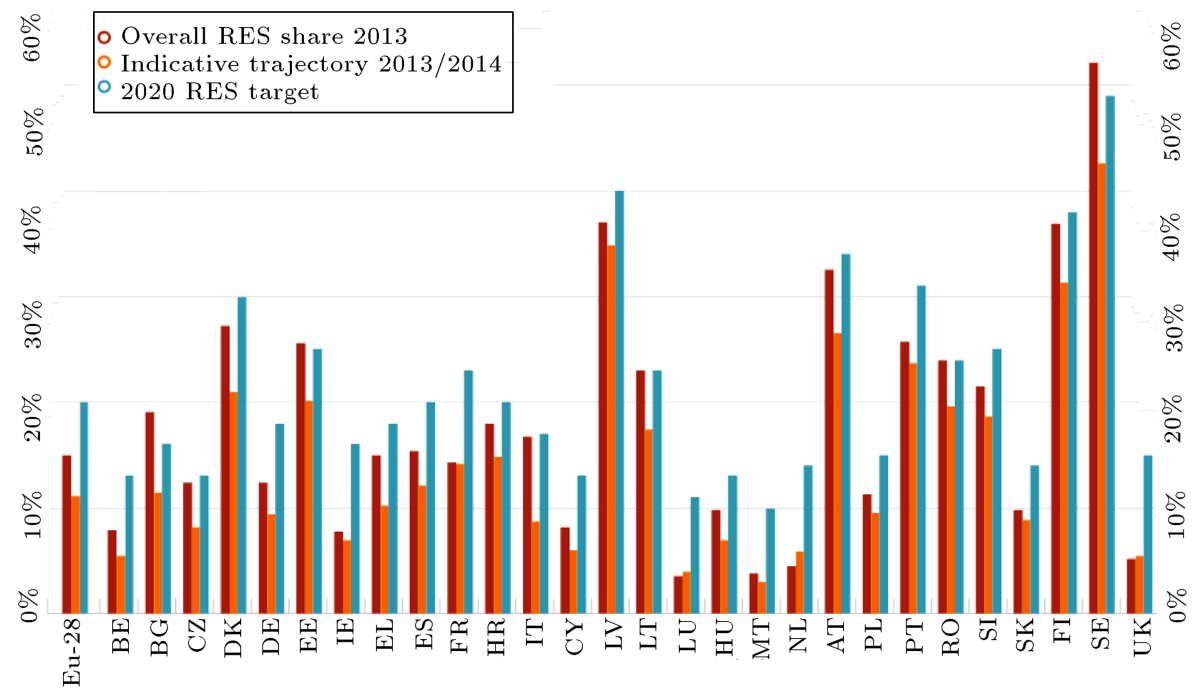

Figure 2. Renewable energy shares in total energy mix and 2020 targets for EU-28 countries (adopted from EU Energy Statistical Pocketbook, 2015). 
other locations in Greece mainly due to natural beauty protection and cultural reasons, in the specific survey, the local population's familiarity with the long-term operation of a lignite-based power station (850 MW) seems to have affected their acceptance.

Another questionnaire study conducted to trace the attitudes and perceptions of 201 households towards renewable energy projects in Western Greece showed that younger, better educated and higher income respondents as a cluster were more possible to accept the implementation of such projects in comparison with respondents who were older, less educated, and economically weaker [23].

\section{Aim and methodology of our research project Thales}

The method of empirical research is the use of a questionnaire survey on random sample/structured interviews of market participants in the energy trading sector with the aim of achieving nationwide coverage. The questionnaire survey is an integral part of the overall investigation of "The Shadow economy (informal sector) in Greece: Size, Causes and Consequences", in the context of Thales Research Project. Regression econometric analysis will be further utilized to enhance the results of the questionnaire research.

Emphasis is given to the qualitative analysis of questionnaire results, aspiring to reveal the opinions of households, enterprises and institutional entities, and public services. It does not aim for the precise percentage regarding the measurement of Greek shadow economy, but aims for the qualitative analysis and the comprehension of the problem so that we can reach essential and thorough proposals for the government in order to contain the problem.

The whole process of questionnaires collection in the Project Thales, including the current research proposal, is innovating based on new technologies (using laptops, the internet, mobile internet, mobiles, SMS, real time distribution of the results, local collection of the answered questionnaires). Moreover, the use of questionnaires with bullet points is a pioneering method for the Greek standards. This kind of questionnaires makes the research extensive since they are read through a professional scanner, special for quick reading and accurate analysis of the results.

It should be noted that the fieldwork has secured funding through the above-mentioned research project. The funding is necessary in order to carry out all the necessary preparatory work for the interview, reproduction, and completion of the questionnaire from the final sample. The configuration of the questionnaire finding suitable questions, the processing of the questionnaire, and the respective analysis in the case of Greek energy sector is part of the whole project.
The purpose of our research project is to research and measure all the various aspects of shadow economy in Greece, including corruption, tax evasion, tax avoidance, social contribution avoidance, undeclared and illegal work, self-consumption, tax morale level, tax compliance level, illegal and criminal acts (black or underground economy, money-laundering, human and drug trafficking, briberies). It covers all economic agents in Greece, such as citizens and corporations (e.g., public servants and private individuals, companies and all professional categories, etc.). The research is also performed at sector levels. It does not aim for the precise percentage regarding the measurement of Greek shadow economy, but aims for the qualitative analysis of questionnaire results and the comprehension of the problem. The implementation of our interviews, scientific games, and economic experiments (tax compliance games) involves at least 2,000 individuals and business owners (in majority small businesses). The project aims to achieve numerous objectives, such as the developing a relevant theoretical background and performing cross-country comparisons, at the regional level with advanced taxation systems.

The innovativeness and originality of our research area and of the wider project are associated with the facts in a way that such an extensive research has never been performed in Greece before; in addition, this study is situated at the peak of the current public and academic debate. Until now, the estimated size of shadow economy in Greece have come to a conclusion only through indirect approaches and methods that are easily applicable, but include a great possibility of faults to exist in the so-called accurate measurement of the shadow economy; they are also unable to determine the factors that cause people to shift toward shadow economy. These indirect approaches to measure shadow economy are the widespread calculations of black economy based on secondary macroeconomic data. The research methodology and the project by considering the weaknesses of a direct approach of measuring the Greek shadow economy (cost is to be incurred for the resources and time designated to manage a large number of questionnaires), however, aspire to be the first that will calculate the shadow economy in Greece by using and analyzing primary data.

Finally, various proposals and structural polices to the Greek Government are expected to be addressed at the finalization of the research on the effective confrontation of black/shadow economy and tax evasion in Greece.

\section{Research findings from our questionnaire survey}

A questionnaire survey and stratified interviews with market participants were conducted during the sec- 
ond semester of 2014, which covered the following two sections of RES: wind energy and solar PV. As mentioned before, the NREAP's compliance scenario projects the installation of almost $7.5 \mathrm{GW}$ of wind power by 2020, together with $2.2 \mathrm{GW}$ of $\mathrm{PVs}$ and $250 \mathrm{MW}$ of concentrating solar power plants; so, the two sections considered by the survey consist of the most significant contributors in the achievement of the overall RES capacity targets by 2020. The survey covered active participants in the regions of central and northern parts of Greece and Crete, where a significant share of installed capacity has been already developed.

The main areas of questions addressed to the participants involved the following aspects:

a) Motivations towards investing in RES;

b) Current obstacles to the implementation of their RES capacity targets, including the existence of any corruption practices;

c) Proposals towards removing the current obstacles;

d) The social acceptance of RES by local communities;

e) The impact of economic crisis on the implementation of the existing investments or the undertaking new ones;

f) The continuation of selling licenses of PV projects and the respective reasons;

g) Their plans for future investments;

h) Their critical evaluation of the loan policy by the banking sector;

i) The previous and projected rate of returns of their investments;

j) Their forecast regarding whether the overall RES targets set in the National Renewable Energy Action Plan by 2020 are attainable.

According to the feedback received by market participants, the following research conclusions from our survey and interviews are presented:

- The favorable framework as set by the Law 3851/ 2010, investments subsidies, tax incentives, grants, and encouraging levels of feed-in tariffs were the most significant motivations in the past for undertaking investments in wind energy and solar PV projects;

- The following are mentioned as among the main obstacles to the implementation of their investment projects: the way of implementation and administration of the current institutional framework; the arbitrary cancellation of contracts signed with smallscale energy producers, delays in the timely payment of energy generated by the competent authorities as per the pre-agreed time schedules; the lengthy licensing procedures which prevail in some cases; intercalary legislation such as the application of special solidarity levy on producers of electricity from RES and the Cogeneration of Heat and Power (CHP), pushed out of the market of the smallerscale investors, the corruptive actions of the state mechanism in some cases [24]; the variation unilaterally by the state authorities of the selling prices per generated $\mathrm{kWh}$ (although as was declared in some case resulted from the significant increase in the installed capacity); the discouraging levels of feed-in tariffs for wind power generation in some areas with low wind potential. With reference to the latter, examination of representative case studies performed by other researchers also emphasizes the criticality of determination of break-even Feed-In-Tariffs (FITs) and the comparison of lifecycle electricity production cost between RES and conventional power stations [25];

- No particular problems were encountered in the social acceptance of the PV parks and also as a result of media advertising, which were enthusiastic in many cases. In contrast, the acceptance of the wind farms was and remains problematic as a result of the practice of some large companies/investors to expropriate private land in the name of the so-called public utility projects. As was underlined, there is a need to increase social acceptance by raising public awareness of the benefits of wind power (including $\mathrm{CO}_{2}$ emissions reductions, security of supply, and economic growth) and of the associated need for supplementary transmission;

- The prolonged economic crisis has indirectly influenced the performance of the undertaken investments, particularly those of small- and mediumscale investors as a result of increased taxation, requirement for tax advance payments, delayed clearance of VAT payments from the side of tax authorities, and shortage of funding facilities from the side of the banking sector. Further, the crisis has facilitated the acquisition of the existing small and large licensed projects by foreign investors, through their participation in Greek corporate vehicles is observed. As has also been mentioned by other researchers, Greece has been affected by an economic crisis that threatens to impede its renewable energy developments unless the country uses RES as a means to escape the crisis $[25,26]$. Further, in line with Metaxas and Tsinisizelis [27], the long-lasting financial crises in Greece and also in other European countries constitute a barrier in taking proper and efficient measures and legislative efforts to boost RES development. This scarce national governance does not succeed to get the "broader picture" and evaluate appropriately the various advantages of an increased, yet well-structured, RES penetration; 
- The investment returns of the undertaken projects were considered to be sufficient by the majority of the respondents, at least in the past period, which could well depend on the date of project inauguration, or specific technology utilized (e.g., solar PV trackers) with the IRR ranging between $10 \%-14 \%$; the rate of return by 2020 will depend on the level of feed-in tariffs. In limited cases, it was mentioned that additional investments may be undertaken until 2020; the "Energy Efficiency at Home" Programme, which provides subsidies for low-income families to replace inefficient burner/boiler systems and installs solar energy water-heaters, can trigger further investments. Our view, however, is that capital costs and risks for investors have amplified, not surprisingly, in recent years as a result of the political, economic, or regulatory uncertainties. According to other studies, the capital costs for onshore wind projects reached $12 \%$ in Greece compared to 3.5$4.5 \%$ in Germany [28];

- The large majority of the respondents in our sample consider that the overall RES targets set in the National Renewable Energy Action Plan by 2020 will be achieved by 2020 . Although our survey covers mainly continental Greece, its extension and consideration of Aegean Sea Islands, particularly those characterized by other studies as high potential energy savings in the residential sector [29], such as Lesbos, Lemnos, Samothrace, Chios, Andros, Patmos, Kea and Kimolos, would provide an extension of our work, and it is planned to be covered during the second quarter of 2016 .

\section{Conclusions}

In a notable change from the position in the past, the Greek government is committed to greening the economy and determining policies and actions to boost the utilization of renewable energy. Law 3851/2010 places encouraging conditions on the evolvement of renewable energy, and the frontward roadmap is described in the 2010 National Renewable Energy Action Plan. The national goal for the proportion of renewable energy in gross final consumption by 2020 exceeds the obligation to the European Union. Achieving the distinct goal for electricity generated from RES will assist Greece to abate carbon use in its power sector. Composite licensing and siting procedures have resulted in extensive setbacks in RES projects. It is noteworthy that Law 3851/2010 has streamlined and cut prolonged licensing process into only some months in several cases, presently [3].

Electricity production from RES is fostered by the feed-in tariffs and investment support (except for PV plants) through a combination of tax incentives, subsidies, and grants. The current system of feed-in tariffs and its validity for most technologies extends up to 20 years. Prompt licensing procedures and munificent subsidies will unquestionably aid to reach targets for renewable energy generation, but allowing for their cost aspect, the government must skillfully manage the efficiency of the feed-in system.

Wind and solar energies are anticipated to grow more rapidly in the Greek renewable energy, but the country maintains widely unexploited potential for biomass, geothermal, and solar thermal energies. Hence, Greece is encouraged to establish a national policy to expand the utilization of these sources of energy.

According to the findings of our questionnaire survey, delays in the timely payment of the energy generated by the competent authorities per the preagreed time schedules, VAT reimbursement issues, and the lack of certainty in the future path of feed-in tariffs consist of the main obstacles and risks that have to be managed, particularly by small-scale investors. The government should consider decreasing the feed-in tariffs in a more predictable and transparent way over time as technologies mature.

Finally, it is worth mentioning that no similar questionnaire survey has been conducted in Greece with the direct involvement of market participants. The completion of the analysis of the final results of the survey is expected to support the development of useful proposals for facilitating the Greek government to finetune its intermediate policy goals, to further its fight against bureaucratic and corrupted procedures, and further ensure that its 2020 renewable energy targets are achieved.

\section{Acknowledgements}

The current paper is presented under the auspices of the THALES Research Programme. THALES Programme has been co-financed by the European Union (European Social Fund - ESF) and Greek national funds through the Operational Program "Education and Lifelong Learning" of the National Strategic Reference Framework (NSRF).

\section{References}

1. Zerhouni, F., Zerhouni, M., Zegrar, M., Benmessaoud, M., Tilmatine, A. and Stambouli, A., "Modelling polycristallin photovoltaic cells using design of experiments", Scientia Iranica, 21(6), pp. 2273-2279 (2014).

2. Ghaedi, A., Abbaspour, A., Fotuhi-Friuzabad, M. and Parvania, M. "Incorporating large photovoltaic farms in power generation system adequacy assessment", Scientia Iranica, 21(3), pp. 924-934 (2014).

3. Carmo, M., Fritz, D., Mergel, J. and Stolten, D. 
"A comprehensive review on PEM water electrolysis", International Journal of Hydrogen Energy, 38(12), pp. 4901-4934 (2013).

4. Reinoso, C., Cutrera, M., Battioni, M., Milone, D. and Buitrago, R. "Photovoltaic generation model as a function of weather variables using artificial intelligence techniques", International Journal of Hydrogen Energy, 37(19), pp. 14781-14785 (2012).

5. Ohara, B., Wagner, M., Kunkle, C., Watson, P., Williams, R., Donohoe, R., Ugarte, K., Wilmoth, R. and Chong, M. "Residential solar combined heat and power generation using solar thermoelectric generation", Journal of Electronic Materials, 44(6), pp. 21322141 (2015).

6. Harman, T. and Zunger, A. "Special issue on research opportunities in photovoltaic semiconductors", Journal of Electronic Materials, 22(1), pp. 0361-5235 (1993).

7. Faridimehr, S. and Niaki, S.T.A. "Optimal strategies for price, warranty length, and production rate of a new product with learning production cost", Scientia Iranica, Transactions E, 20(6), pp. 2247-2258 (2013).

8. Shavandi, H. and Zare, A.G. "Analyzing the price skimming strategy for new product pricing", Scientia Iranica E, 20(6), pp. 2099-2108 (2013).

9. Zavadskas, E., Antucheviciene, Turskis, J. and Adeli, H. "Hybrid multiple-criteria decision-making methods: A review of applications in engineering", Scientia Iranica, 23(1), pp. 1-20 (2016).

10. Tsoutsos, T., Maria, E. and Mathioudakis, V. "Sustainable siting procedure of small hydroelectric plants: the Greek experience", Energy Policy, 35(5), pp. 29462959 (2007).

11. Maria, E. and Tsoutsos, T. "The sustainable management of renewable energy sources installations: legal aspects of their environmental impact in small Greek islands", Energy Conversion and Management, 45, pp. 631-638 (2004).

12. Zografakis, N., Menegaki, A. and Tsagarakis, K. "Effective education for energy efficiency", Energy Policy, 36, pp. 3226-3232 (2008).

13. International Energy Agency, IEA, Key World Energy Statistics (2014).

14. Eurostat, Statistics explained, available at: http:// ec.europa.eu/eurostat/statistics-explained/index.php/ Renewable_energy_statistics. Last accessed on 17/ $08 / 15$.

15. International Energy Agency, "Energy policies of IEA countries, Greece review 2011", OECD/IEA, France, (2011).

16. European Commission "ENERGY: country factsheets", Directorate-General for Energy, V.1.3 (2012).

17. Intelligent Energy Europe, Survey Report: Progress in Energy Efficiency Policies in the EU Member States
- the Experts Perspective, Findings from the Energy Efficiency Watch Project, O.Ö. Energiesparverband, Linz, Austria (2012).

18. Kontakos, P. and Zhelyazkova, V. "Energy infrastructure projects of common interest in the SEE, Turkey \& Eastern Mediterranean", In Energy Systems and Management, Chapter 25, A.N. Bilge, A.Ö. Toy and M.E. Günay, Eds., Istanbul Bilgi University - Palmet, Istanbul: Springer International Publishing, pp. 261267 (2015).

19. European Union, Statistical Pocketbook, 27 (2015).

20. Erbach, G. "Promotion of renewable energy sources in the EU", In Depth Analysis, European Parliamentary Research Service, PE 583.810, ISBN 978-92-823-93536, pp. 1-20 (2016). DOI: 10.2861/062931

21. European Union, Assessing Renewables Policy in the $E U$, DiaCore project (2016).

22. Kaldellis, J., Kapsali, M. and Katsanou, E. "Renewable energy applications in Greece. What is the public attitude?", Energy Policy, 3, pp. 37-48 (2012).

23. Paravantis, J., Stigka, E. and Mihalakakou, G. "An analysis of public attitudes towards renewable energy in Western Greece", The 5th International Conference on Information, Intelligence, Systems and Applications, pp. 300-305 (2014). DOI: 10.1109

24. Bitzenis, A. and Kontakos, P. "Energy trade and tax evasion in the oil sector in Greece", 7th Annual Conf. of the Euromed Academy, Kristiansand, Norway (September 2014).

25. Zafirakis, D., Chalvatzis, K. and Kaldellis, J. "Socially just", support mechanisms for the promotion of renewable energy sources in Greece", Renewable and Sustainable Energy Reviews, 21, pp. 478-493 (2013).

26. Menegaki, A. and Gurluk, S. "Greece \& Turkey; assessment and comparison of their renewable energy performance", International Journal of Energy Economics and Policy, 3(4), pp. 367-383 (2013).

27. Metaxas, A. and Tsinisizelis, M. "The development of renewable energy governance in Greece. Examples of a failed (?) policy", In Renewable Energy Governance, 23, pp. 155-168 (2013).

28. REN 21 "Renewables 2016: global status report", Renewable Energy Policy Network for the 21st Century, pp. 1-272 (2016).

29. Mondol, J. and Koumpetsos, N. "Overview of challenges, prospects, environmental impacts and policies for renewable energy and sustainable development in Greece", Renewable and Sustainable Energy Reviews, 1(23), pp. 431-442 (2013).

\section{Biographies}

Aristidis Bitzenis is a Professor of International Entrepreneurship and Foreign Direct Investment at the University of Macedonia in Thessaloniki (Greece) at the Department of International and European 
Studies. He is also a Tutor in the Hellenic Open University of Patras (Greece). His research record and forthcoming publications are twelve books (six of them are in the Greek language), 25 book chapters, fifteen entries in encyclopedias, 45 refereed journal articles, 25 refereed papers in conference proceedings, and participation in fifteen research grants. $\mathrm{He}$ is an active research officer participating in various European Union funded research programmes, such as Entrepreneurship and Innovation (DASTA), Preparing Innovative Academic Material for Entrepreneurship, Hellenic Academic Open courses, Thalis (Education and Lifelong Learning), Egnatia VAE Cross-border vertical axes of entrepreneurship in support of youth and women, Encouragement of Entrepreneurship \& Actions that cope with the restructuring of the economy, enhancement of the competitiveness and restructuring of the food subsectors through benchmarking F.IND Consulting.

Panagiotis Kontakos is an Assistant Professor in International Business, at the University of Central Lancashire, Cyprus, and Adjunct Faculty Member at the Hellenic Open University. His current research interests are focused on the areas of global entrepreneurship, energy economics and circular economy. He is a member of various editorial boards and has presented or published papers extensively in international scientific and business conferences and journals. Dr. Kontakos's previous long professional experience for a period of 16 years was centered on the corporate governance of financial institutions in several SEE countries. Further, he has been certified by the Global Association of Risk Professionals (GARP) as an Energy Risk Professional (ERP). He maintains professional memberships in GARP, Dubai Chapter, as a voting member and also in the Institute of Operational Risk (IOR), London. His post-doctoral research in the areas of energy trade \& finance and business ethics was cofinanced by EU \& Greek national funds.

Charisios Kafteranis is the Administration Manager at the Center for Technology Research \& Innovation (CETRI). He holds degrees in Business Administration and Engineering Environment and Master in European Policies of Youth. He has worked as a freelancer and as a business consultant. Mr Kafteranis has participated in many European programs and projects (DASTA, "Administrative Reform 2007-2013", Education and Lifelong learning, Interreg III, INAP, and others). He is an external partner at ELKE research committee of the University of Macedonia and member of the International Conference on International Business. He has published books and participated in international conferences in the areas of entrepreneurship and innovation. 